\title{
Mechanism of Action of Glatiramer Acetate in Treatment of Multiple Sclerosis
}

\author{
Martin S. Weber, ${ }^{*}$ Reinhard Hohlfeld, ${ }^{\dagger \dagger}$ and Scott S. Zamvil* \\ *Department of Neurology and Program in Immunology, University of California, San Francisco, CA 94143; ${ }^{\dagger}$ Institute for \\ Clinical Neuroimmunology, Klinikum Grosshadern, Ludwig Maximilians University, Munich, 81377, Germany; and ${ }^{\ddagger}$ Department \\ of Neuroimmunology, Max Planck Institute of Neurobiology, Martinsried, 82152, Germany
}

Summary: Glatiramer acetate (GA) (Copolymer-1, Copaxone, Teva, Israel, YEAK) is a polypeptide-based therapy approved for the treatment of relapsing-remitting multiple sclerosis. Most investigations have attributed the immunomodulatory effect of GAs to its capability to alter T-cell differentiation. Specifically, GA treatment is believed to promote development of Th2-polarized GA-reactive $\mathrm{CD}^{+}{ }^{+} \mathrm{T}$-cells, which may dampen neighboring inflammation within the central nervous system. Recent reports indicate that the deficiency in $\mathrm{CD} 4{ }^{+} \mathrm{CD} 25^{+} \mathrm{FoxP}^{+}$regulatory $\mathrm{T}$ - cells in multiple sclerosis is restored by GA treatment. GA also exerts immunomodulatory activity on antigen presenting cells, which participate in innate immune responses. These new findings represent a plausible explanation for GA-mediated T-cell immune modulation and may provide useful insight for the development of new and more effective treatment options for multiple sclerosis. Key Words: Multiple sclerosis, glatiramer acetate, immunomodulatory agents, mechanism of action, antigen presenting cells.

\section{INTRODUCTION}

Glatiramer acetate (GA) (Copolymer-1, Copaxone, Teva, Israel, YEAK) is a pool of synthetic peptides randomly composed of L-tyrosine (Y), L-glutamic acid (E), L-alanine (A), and L-lysine $(\mathrm{K})$ with an average length of 40 to 100 residues. GA was synthesized in this manner more than 30 years ago to most closely resemble the encephalitogenic properties of myelin basic protein (MBP), one suspected auto-antigen in multiple sclerosis (MS). Surprisingly, instead of inducing experimental autoimmune encephalomyelitis (EAE), the murine model of MS, immunizations with GA protected mice from subsequent attempts to induce EAE. ${ }^{1}$ This seminal observation was followed by various clinical trials. Whereas early open-label studies already suggested clinical benefit in the $1980 \mathrm{~s},{ }^{2,3}$ these findings had to be interpreted with caution as drug production was not yet standardized. In 1991, a phase III multicenter, doubleblind, placebo-controlled trial with standardized GA preparation was initiated in 11 medical centers in the

Address correspondence and reprint requests to: Scott S. Zamvil, M.D., Ph.D., Department of Neurology, Program in Immunology, University of California, San Francisco, 513 Parnassus Avenue, S-268, San Francisco, CA 94143. E-mail: zamvil@ ucsf.neuroimmnunol.org.
United States, with 251 relapsing-remitting MS patients. ${ }^{4}$ Within two years of treatment, the relapse rate decreased approximately $30 \%$ in GA-treated patients leading to approval of GA treatment of MS in many countries worldwide in 1995. A later double-blind, placebo-controlled study demonstrated a reduction in the number of gadolinium-enhancing lesions in patients receiving GA compared to a placebo during a nine-month study period. ${ }^{5}$ Additional data showed that GA may also have a favorable effect in preventing tissue loss at a later diseased stage. ${ }^{6,7}$ Based on these favorable clinical and imaging data, subcutaneously administered GA is one of the most widely prescribed drugs used today for the treatment of relapsing-remitting MS.

Many investigators have attempted to address the immunologic basis for the clinical effects of GA in MS and MS models. ${ }^{89}$ Although different potential mechanisms have been considered, most investigations have attributed the immunomodulatory activity of GA to alterations in T-cell antigen reactivity, focusing on its influence on the adaptive immune response. Early in vitro studies established that GA can bind to major histocompatibility complex (MHC) class II molecules and suggested that GA might preferentially alter presentation of myelin antigens to auto-reactive T-cells. ${ }^{10,11}$ Studies in EAE and MS have extensively demonstrated that GA treatment 
promotes development of Th2-polarized GA-reactive $\mathrm{CD}^{+}{ }^{+} \mathrm{T}$ cells. ${ }^{1,12-14}$ These Th2 cells can potentially accumulate in the $\mathrm{CNS}^{15}$ where they might release antiinflammatory cytokines ${ }^{12,15-17}$ and neurotrophic factors, ${ }^{18}$ dampening the activity of nearby auto-aggressive $\mathrm{T}$ cells, a process known as "bystander suppression." 15 Recent reports indicate that GA treatment also exerts immunomodulatory activity on antigen presenting cells (APCs) ${ }^{19-23}$ a part of the innate immune system. These newer findings may provide a plausible explanation for the observed Th2 deviation under GA treatment and raise the question as to whether GA is solely an antigenspecific T cell-directed immunotherapeutic agent as currently assumed. In this article, we review the various effects of GA on the adaptive and innate immune system and describe how these two arms of the immune system interact with one another during GA therapy.

\section{Effects on the adaptive immune system}

As with conventional peptide antigens, GA can bind to MHC class II molecules on the surface of APCs. ${ }^{10,24}$ In association with MHC class II molecules, GA is recognized by $\mathrm{T}$ cells via their antigen-specific T-cell receptor. Early in vitro studies indicated that GA may compete with myelin antigens for the binding to MHC class II. Specifically, it was observed that GA binding to MHC class II could inhibit the activation of $\mathrm{T}$ cell lines specific for MBP. ${ }^{25}$ However, a later study demonstrated that the stereoisomer of GA, D-GA, which contains solely Damino acids, could effectively bind to MHC class $\mathrm{II}^{26}$ but failed to suppress EAE. ${ }^{27}$ These findings indicate that GA may not primarily act as an MHC class II antagonist.

It is well established that in most MS patients, GA treatment induces a population of $\mathrm{CD}^{+}$GA-reactive Th2 cells, ${ }^{12-14,28}$ which is associated with clinical benefit. $^{29}$ It seems very unlikely that sufficient amounts of GA can reach the CNS to locally activate GA-reactive T cells. It is believed that GA-reactive Th2 cells are generated in the periphery, accumulate (along with pathogenic non-GA-specific elements) in the CNS of patients with MS and release anti-inflammatory cytokines in a process termed "bystander suppression" (see FIG. 1). Many studies in EAE and MS have generated the concept that GA-reactive Th2 cells may be reactivated within the CNS through cross-recognition of myelin antigen. ${ }^{12,16}$ This assumption was supported by two observations. First, GA-reactive Th2 cells could be identified in the CNS of GA-treated mice protected from EAE. ${ }^{15}$ Second, in some but not all studies, ${ }^{30}$ several GA-specific Th2 cell lines generated from MS patients or mice could cross react with MBP at the level of cytokine secretion. ${ }^{12,15-17,31}$

$\mathrm{CD} 4{ }^{+} \mathrm{CD} 25^{+}$regulatory $\mathrm{T}$ cells (Treg) are an important subclass of regulatory cells that engage in the maintenance of immunologic tolerance by actively suppressing self- reactive lymphocytes. ${ }^{32,33}$ Forkhead transcription factor Foxp3 is the key transcription factor in the physiological development of Treg. ${ }^{34}$ Its genetic defect results in impaired function of Treg, which is associated with in an autoimmune and inflammatory syndrome in humans as well as in mice. ${ }^{35}$ Similarly, the experimental deletion of Treg in mice causes various spontaneous organ-specific autoimmune diseases. ${ }^{36}$ Viglietta et al. ${ }^{37}$ reported that in patients with MS, similar to other autoimmune conditions, ${ }^{38}$ effector function and frequency of Treg is significantly decreased in the peripheral blood. Several studies provided evidence for a role and mechanism of action of GA in the induction of $\mathrm{CD} 4{ }^{+} \mathrm{CD} 25^{+}$Treg. In vitro exposure to GA resulted in an elevated production of interleukin-10 (IL)-10 by Treg. ${ }^{39}$ In another study, GA promoted the conversion of $\mathrm{CD} 4{ }^{+} \mathrm{CD} 25^{-}$to $\mathrm{CD} 4{ }^{+} \mathrm{CD} 25^{+}$ Treg through the activation of Foxp $3 .^{40} \mathrm{GA}$ treatment led to a significant increase in Foxp3 expression in $\mathrm{CD}^{+} \mathrm{T}$ cells in MS patients whose Foxp3 expression was reduced at baseline. GA-reactive $\mathrm{CD} 4{ }^{+} \mathrm{CD} 25^{+} \mathrm{T}$-cell lines generated from GA-treated MS patients expressed high levels of Foxp3 that correlated with increased T-cell regulation. ${ }^{40}$ Thus, besides the well-known preferential Th2 differentiation of $\mathrm{T}$ cells, GA appears to normalize frequency and function of Treg in MS, which represents an additional immunomodulatory effect of GA.

More recently, it was reported that GA treatment also induces a population of $\mathrm{CD}^{+}$GA-reactive $\mathrm{T}$ cells. In untreated MS patients, GA-reactive $\mathrm{CD} 8^{+}$T-cell responses were found to be significantly lower compared with healthy individuals. Treatment with GA restored these $\mathrm{CD}^{+}{ }^{+}$responses ${ }^{41}$ and enhanced release of IFN- $\gamma$ by these cells, ${ }^{42}$ which appears to be associated with a positive clinical response. ${ }^{42}$ Although the in vivo function of these cells is still not entirely understood, a recent report indicated that GA-reactive $\mathrm{CD} 8+\mathrm{T}$ cells may suppress pro-inflammatory effector T-cell function in a manner similar to $\mathrm{CD} 4^{+} \mathrm{CD} 25^{+}$Treg. ${ }^{43,44}$

Besides activation and alteration of $\mathrm{T}$ cells, GA treatment also induces a humoral response to itself in most patients, which peaks approximately 3 months after treatment initiation. ${ }^{45}$ Just as individuals who are naive to GA treatment sometimes have pre-existing (naive) GA reactive $\mathrm{T}$ cells, ${ }^{28}$ some untreated MS patients reveal an unprimed humoral response against GA, mainly of an IgM, IgG1, and IgG2 isotype. ${ }^{46}$ GA-treated MS patients also produce IgG1 and IgG2 anti-GA antibodies, but in contrast to unexposed individuals, GA-treated MS patients frequently develop high titers of IgG4 antibodies against GA. ${ }^{46}$ Preferential secretion of IgG4 antibodies might occur secondary to the induction of GA-reactive Th2 cells, as isotype switching to IgG4 is regulated by the Th2 cytokine IL-4. To date, it is considered controversial whether antibodies against GA are of clinical relevance. In general, IgG4 antibodies have strong neu- 


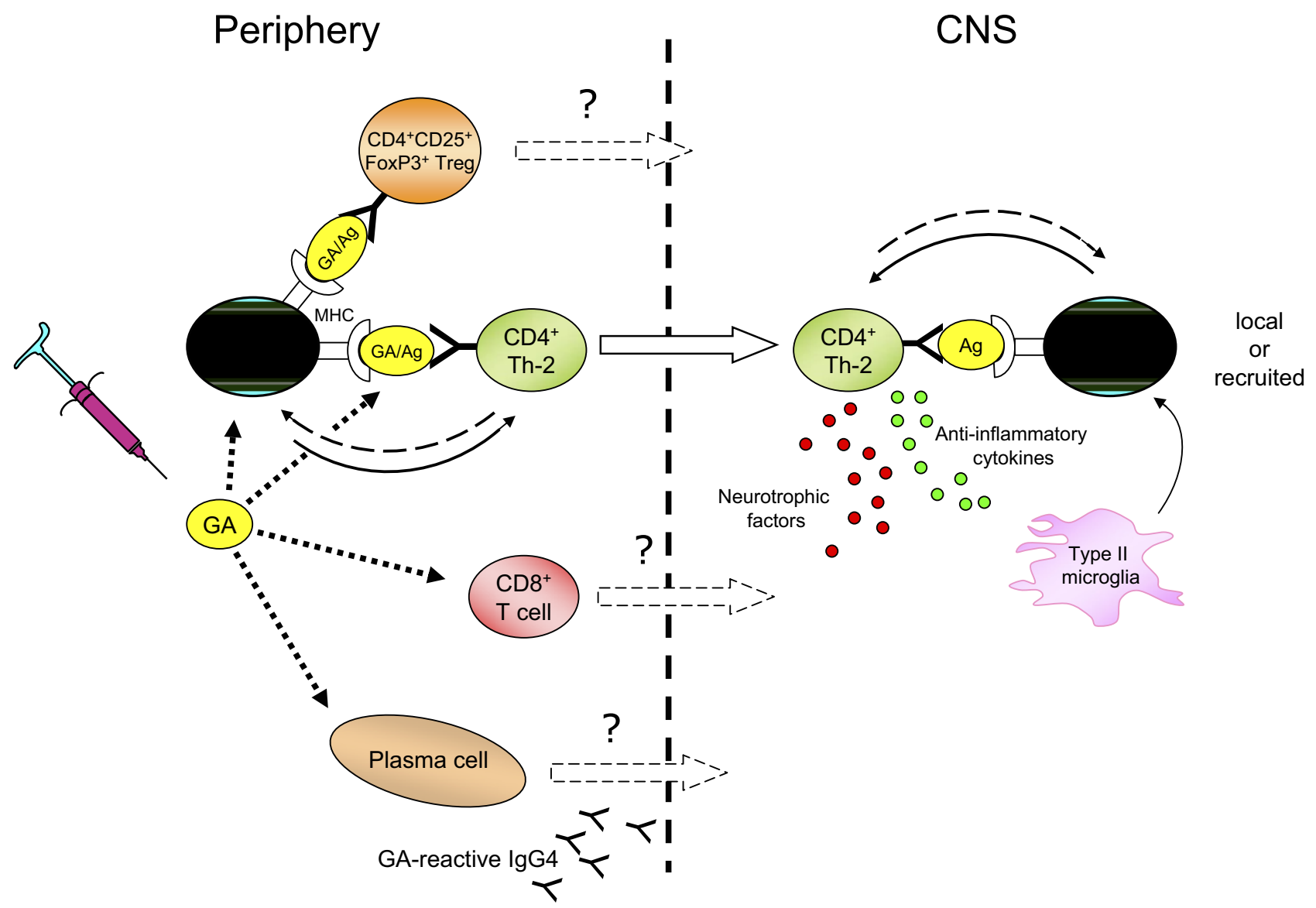

FIG. 1. Cross-talk between type II antigen presenting cells (APCs) and regulatory T-cell populations in glatiramer acetate (GA)-mediated immune modulation. GA treatment exerts effects on APC and T cells that result in the induction of a specific population of Th2 cells and $\mathrm{CD}^{+}{ }^{+} \mathrm{CD} 25^{+} \mathrm{FoxP}^{+}$regulatory T cells (Treg) in the periphery. Type II APC and Th2 cells may facilitate the development of each in a positive feedback mechanism, as type-2 monocytes tend to induce Th2 cells, and Th2 cell-derived anti-inflammatory cytokines may promote development of type II APC. GA-reactive Th2 cells are believed to cross the blood-brain barrier and to be locally reactivated within the CNS through cross recognition of myelin antigen. In response, these cells may secrete anti-inflammatory cytokines and neurothrophic factors dampening neighboring inflammation ("bystander suppression"). Another feedback loop between APC and T cells may develop within the CNS, as Th2-cytokines might promote type II differentiation of resident APC, such as microglia. GA treatment is also associated with induction of GA-reactive $\mathrm{CD}^{+} \mathrm{T}$ cells, although their in vivo function remains to be determined. Finally, consistent with the Th2 shift, GA-reactive plasma cells secrete anti-GA antibodies $(<)$, preferentially of an IgG4 isotype. Whether these antibodies enter the CNS or may neutralize some of the immunomodulatory effects of GA is not yet known. (GA-Ag = glatiramer acetate antigen; ? = Presumed transmigration of immune cells across the blood-brain barrier.)

tralizing activity, although they do not bind to fragment crystallizable $(\mathrm{Fc})$ receptors or activate the complement system. However, serum from GA-treated patients containing antibodies against GA did not inhibit the ability of GA to stimulate GA-reactive T cells, indicating that in vitro anti-GA Ig had no neutralizing effect. ${ }^{45}$ Interestingly, Brenner et al. ${ }^{47}$ reported that relapse-free patients displayed higher titers against GA than patients with an active disease course under GA treatment, indicating a beneficial rather than effect-neutralizing role of antibodies against GA. In fact, in an animal model of CNS demyelinating disease, GA-specific antibodies were shown to promote myelin repair, ${ }^{48}$ an effect which might contribute to the proposed neuroprotective properties of GA in MS.

\section{Effects on the innate immune system}

Although past investigations of GA primarily focused on its effects on the adaptive immune system, especially on $\mathrm{T}$ cells, emerging evidence supports the concept that GA may also act on APCs. The interaction between APCs and T cells is fundamental for any adaptive T-cell immune response. Several groups have reported that in vitro GA treatment leads to a broad antigen-nonspecific alteration of APC function. ${ }^{19-21,49-52}$ Possibly the first report regarding the effect of GA on the innate immune system was derived from an in vitro study in which GA altered the activation of a human monocytic cell line. ${ }^{49}$ Specifically, GA inhibited the induction of HLA proteins as well as the release of tumor necrosis factor (TNF) and cathepsin B by THP-1 cells. In vitro GA treatment was 
also shown to alter the activation status of freshly isolated human monocytes. ${ }^{19,20}$ Weber et al. ${ }^{19}$ reported that GA inhibited lipopolysaccharide (LPS)-mediated expression of APC activation markers, including CD150/ SLAM, CD25, and CD69. Furthermore, GA-treated monocytes released significantly lower levels of TNFand IL-12, two inflammatory Th1-polarizing cytokines. Another study demonstrated that GA treatment not only reduced the release of inflammatory cytokines, but also enhanced production of Th2 polarizing IL-10 by monocytes. ${ }^{20}$ A similar cytokine shift was observed in microglial cells, an APC population that is believed to have a key role in the reactivation of T cells within the CNS. In vitro-generated human dendritic cells also released less $\mathrm{TNF}^{21}$ and IL- $12^{50}$ on in vitro GA exposure. Most notably, GA-treatment of dendritic cells promoted Th2 differentiation of naive $\mathrm{T}$ cells without affecting APC capability for inducing T-cell proliferation. ${ }^{21}$

Two independent studies investigated how GA affects monocytes in MS patients. In both studies, monocytes were freshly isolated from GA-treated patients without any additional in vitro exposure to GA. Compared to untreated MS patients and healthy subjects, monocytes from GA-treated MS patients expressed significantly lower levels of the activation marker CD150/SLAM and released less TNF on stimulation with low concentration of LPS. ${ }^{19}$ In the second study, Kim and colleagues ${ }^{20}$ reported that the basal and induced release of IL-10 was significantly enhanced in monocytes from GA-treated patients, whereas the production of IL-12 was reduced, defining an anti-inflammatory "type II" monocyte phenotype. These studies clearly indicate a systemic effect of GA treatment on monocytes that may promote Th2 differentiation of $\mathrm{T}$ cells in vivo. Theoretically, these findings raise the possibility that GA treatment may compromise innate immune responses in GA-treated MS patients. However, GA-treatment does not appear to be predisposed to infections. In this regard, one in vitro finding might be of relevance (i.e., GA only inhibited activation of monocytes that were challenged with suboptimal concentrations of toll-like receptor ligands, such as LPS).$^{19}$ Higher concentrations of LPS could override the inhibitory effect of GA, which could explain why the capability of monocytes to efficiently clear infections is not diminished in GAtreated MS patients. Future longitudinal studies are necessary to define whether initiation of GA treatment truly leads to a reduction of APC reactivity in the individual MS patient. This type of study will also allow correlation between altered APC reactivity and a drug-related benefit to determine the extent of the clinical relevance of these GA-mediated effects on the APCs.

\section{Cross-talk between type II APC and regulatory T- cell populations}

It has become established that the phenotype of APC influences differentiation of $\mathrm{T}$ cells and that reciprocally differentiated $\mathrm{T}$ cells modify APC function. In this regard, monocytes cultured with Th2 supernatants developed a phenotype similar to GA-treated monocytes. This finding indicates that GA-reactive Th2 cells can exert a positive feedback on the development of type II monocytes. In fact, type II monocyte development may even occur secondary to the induction of GA-reactive Th2 cells. However, other evidence suggests the opposite scenario (i.e., that APCs may be the primary target of GA and that GA-induced type II APCs mediate T-cell deviation). First, in vitro, GA exerted a direct effect on various APC populations resembling its effect in vivo, in the absence of T cells. ${ }^{19,20}$ These GA-treated APCs were capable of promoting development of Th2 cells when co-cultured with naive (untreated) Th0 cells in the absence of GA. ${ }^{21}$ Second, in vivo GA treatment exerted a systemic effect on monocytes and possibly on monocytederived APCs. However, the frequency of GA reactive Th2 cells in the peripheral blood of GA-treated MS patients is only approximately 1 in 20,000 , raising the question as to whether Th2 cytokines derived from these cells could be sufficient to mediate type II APC development. Most strikingly, studies in genetically altered mice indicate that in vivo GA treatment can induce type II monocytes in the absence of T cells. ${ }^{53}$ Further studies are necessary to determine the pathway by which GA treatment may alter APC and T-cell function in MS patients.

Assuming that APCs are the primary target through which GA mediates T-cell immune deviation, one would anticipate that Th2 deviation and/or induction of Treg should not be restricted to GA-reactive T cells. A recent study by Allie et al. ${ }^{54}$ investigated the phenotype of T-cell lines specific for GA, MBP, or tetanus toxoid generated from MS patients before and after GA treatment. T-cell differentiation was assessed by the ratio between IFN- $\gamma$ and IL-5 release. In this longitudinal study, in vivo GA treatment biased differentiation of all $\mathrm{T}$ cell lines toward a Th2 phenotype, indicating that Th2 differentiation occurred independent of T-cell antigen specificity. ${ }^{54}$ However, another study did not describe an antigen-independent Th2 deviation of established T-cell responses on GA treatment, and supported the concept that $\mathrm{Th} 2$ deviation may primarily occur in GA-reactive $\mathrm{T}$ cells. $^{42}$ Although apparently conflicting, both findings might be valid. First, a cross-sectional study comparing untreated patients to GA-treated patients may be less sensitive to detect minor changes in T-cell differentiation compared to a longitudinal study investigating the same patients before and after treatment. Second, it is plausible that an APC-driven Th2 deviation may be pronounced in 
GA-reactive T cells, as every APC that presents GA should have been in contact with GA and undergone type II differentiation prior to T-cell activation. The concept of an antigen-nonspecific effect of GA is further supported by the fact that GA treatment has been shown to be clinically beneficial in other models of autoimmune or inflammatory conditions, such as arthritis, uveoretinitis, ${ }^{55}$ inflammatory bowel disease, ${ }^{56}$ and graft rejection. $^{57}$

Although $\mathrm{T}$ cells might not be the primary target of GA, they are most likely the effector cells of GA-mediated immune modulation. Deficiencies in regulatory $\mathrm{T}$ cells have been associated with MS pathogenesis ${ }^{38}$ and GA-mediated restoration of T-cell regulation correlates with clinical benefit. ${ }^{40}$ In EAE, adoptive transfer of GAreactive $\mathrm{T}$ cells alone can inhibit EAE induction by various encephalitogens, ${ }^{16,31,58}$ similar to GA treatment itself, and GA-reactive T cells accumulate in the CNS of protected animals. Thus, whereas GA may mediate a primary effect on APC independent of T cells, the type II APC-induced regulatory $\mathrm{T}$ cells may be the effector cells of GA-mediated immune modulation.

\section{Possible neurotrophic effects}

Some experimental data indicate that GA may have direct neuroprotective properties. In vitro, GA-reactive T cells can produce neurotrophic factors such as brainderived neurotrophic factor (BDNF). ${ }^{17,18} \mathrm{BDNF}$ is an important factor for differentiation and survival of neurons and is required for maintenance of various glial cell functions. ${ }^{59}$ Although the ability to produce BDNF is unlikely to be restricted to GA-reactive $\mathrm{T}$ cells, it may relate to the activation status of immune cells (e.g., $\mathrm{T}$ cells).$^{60}$ In this regard, the continuous activation by daily GA application may promote BDNF production of GAreactive $\mathrm{T}$ cells in vivo. As activation of immune cells also facilitates their transmigration across the bloodbrain barrier, ${ }^{61}$ accumulation of BDNF-producing GAreactive $\mathrm{T}$ cells within the CNS of patients with MS may occur, in proportion to the population frequency of these cells. This concept is supported by findings derived from EAE studies. Adoptively transferred GA-reactive T cells are detected within the CNS of mice with $\mathrm{EAE}^{15}$ and produce BDNF in situ. ${ }^{62}$ These putative neurotrophic effects of GA may not be restricted to CNS autoimmune disease. In an optic-nerve injury model, GA-specific T cells prevented the secondary degeneration of axons and similarly accumulated at the site of injury producing neurotrophic factors. ${ }^{63}$ In an animal model of glaucoma, GA reduced loss of retinal ganglion cells without affecting intraocular pressure. ${ }^{64} \mathrm{GA}$ administration protected motor neurons from acute and chronic degeneration ${ }^{65}$ and adoptive transfer of GA-reactive $\mathrm{T}$ cells enhanced survival of dopaminergic neurons in a mouse model of Parkinson's disease. ${ }^{66,67}$ Thus, GA may exert neurotro- phic and/or protective properties in addition to immunomodulatory effects. Their relevance in human neurodegenerative diseases, including MS, remains to be determined.

\section{CONCLUSIONS}

Although GA is one of the most widely prescribed drugs for treatment of relapsing-remitting MS, its mechanism of action is still not entirely understood. GA treatment induces a preferential Th2 deviation of $\mathrm{T}$ cells and promotes restoration of frequency and function of Treg in MS. Recent reports demonstrated that GA also exerts immunomodulatory effects on APCs, such as monocytes. These new findings may provide a plausible explanation for GA-mediated T-cell immune modulation. Whereas it remains to be determined whether APCs, T cells, or both are the primary pharmacological target for GA, immune modulation of APC and T cells appears to engage a positive feedback mechanism. These novel observations should contribute to a better understanding of the mechanism of action of GA and may provide useful insight for the development of new and more efficient agents.

\section{REFERENCES}

1. Teitelbaum D, Meshorer A, Hirshfeld T, Arnon R, Sela M. Suppression of experimental allergic encephalomyelitis by a synthetic polypeptide. Eur J Immunol 1971;1:242-248.

2. Bornstein MB, Miller AI, Teitelbaum D, Arnon R, Sela M. Multiple sclerosis: trial of a synthetic polypeptide. Ann Neurol 1982; 11:317-319.

3. Bornstein MB, Miller A, Slagle S, et al. A pilot trial of Cop 1 in exacerbating-remitting multiple sclerosis. N Engl J Med 1987;317: 408-414.

4. Johnson KP, Brooks BR, Cohen JA, et al. Copolymer 1 reduces relapse rate and improves disability in relapsing-remitting multiple sclerosis: results of a phase III multicenter, double-blind, placebocontrolled trial. Neurology 1995;45:1268-1276.

5. Comi G, Filippi M, Wolinsky JS. European/Canadian multicenter, double-blind, randomized, placebo-controlled study of the effects of glatiramer acetate on magnetic resonance imaging-measured disease activity and burden in patients with relapsing multiple sclerosis. European/Canadian Glatiramer Acetate Study Group. Ann Neurol 2001;49:290-297.

6. Filippi M, Rovaris M, Rocca MA, Sormani MP, Wolinsky JS, Comi G. Glatiramer acetate reduces the proportion of new MS lesions evolving into "black holes." Neurology 2001;57:731-733.

7. Sormani MP, Bruzzi P, Comi G, Filippi M. The distribution of the magnetic resonance imaging response to glatiramer acetate in multiple sclerosis. Mult Scler 2005;11:447-449.

8. Neuhaus O, Farina C, Wekerle H, Hohlfeld R. Mechanisms of action of glatiramer acetate in multiple sclerosis. Neurology 2001; 56:702-708.

9. Farina C, Weber MS, Meinl E, Wekerle H, Hohlfeld R. Glatiramer acetate in multiple sclerosis: update on potential mechanisms of action. Lancet Neurol 2005;4:567-575.

10. Fridkis-Hareli M, Teitelbaum D, Gurevich E, et al. Direct binding of myelin basic protein and synthetic copolymer 1 to class II major histocompatibility complex molecules on living antigen-presenting cells_-specificity and promiscuity. Proc Natl Acad Sci U S A 1994;91:4872-4876.

11. Teitelbaum D, Fridkis-Hareli M, Arnon R, Sela M. Copolymer 1 inhibits chronic relapsing experimental allergic encephalomyelitis induced by proteolipid protein (PLP) peptides in mice and inter- 
feres with PLP-specific $\mathrm{T}$ cell responses. J Neuroimmunol 1996;64:209-217.

12. Neuhaus O, Farina C, Yassouridis A, et al. Multiple sclerosis: comparison of copolymer-1- reactive $\mathrm{T}$ cell lines from treated and untreated subjects reveals cytokine shift from $\mathrm{T}$ helper 1 to $\mathrm{T}$ helper 2 cells. Proc Natl Acad Sci U S A 2000;97:7452-7457.

13. Dhib-Jalbut S. Mechanisms of action of interferons and glatiramer acetate in multiple sclerosis. Neurology 2002;58(8 Suppl 4):S3-9.

14. Duda PW, Schmied MC, Cook SL, Krieger JI, Hafler DA. Glatiramer acetate (Copaxone) induces degenerate, Th2-polarized immune responses in patients with multiple sclerosis. J Clin Invest 2000;105:967-976.

15. Aharoni R, Teitelbaum D, Leitner O, Meshorer A, Sela M, Arnon R. Specific Th2 cells accumulate in the central nervous system of mice protected against experimental autoimmune encephalomyelitis by copolymer 1 . Proc Natl Acad Sci U S A 2000;97:1147211477.

16. Aharoni R, Teitelbaum D, Sela M, Arnon R. Copolymer 1 induces $\mathrm{T}$ cells of the $\mathrm{T}$ helper type 2 that crossreact with myelin basic protein and suppress experimental autoimmune encephalomyelitis. Proc Natl Acad Sci U S A 1997;94:10821-10826.

17. Chen M, Gran B, Costello K, Johnson K, Martin R, Dhib-Jalbut S. Glatiramer acetate induces a Th2-biased response and cross reactivity with myelin basic protein in patients with MS. Mult Scler 2001;7:209-219.

18. Ziemssen T, Kumpfel T, Klinkert WE, Neuhaus O, Hohlfeld R. Glatiramer acetate-specific T-helper 1- and 2-type cell lines produce BDNF: implications for multiple sclerosis therapy. Brainderived neurotrophic factor. Brain 2002;125(Pt 11):2381-2391.

19. Weber MS, Starck M, Wagenpfeil S, Meinl E, Hohlfeld R, Farina C. Multiple sclerosis: glatiramer acetate inhibits monocyte reactivity in vitro and in vivo. Brain 2004;127(Pt 6):1370-1378.

20. Kim HJ, Ifergan I, Antel JP, et al. Type 2 monocyte and microglia differentiation mediated by glatiramer acetate therapy in patients with multiple sclerosis. J Immunol 2004;172:7144-7153.

21. Vieira PL, Heystek HC, Wormmeester J, Wierenga EA, Kapsenberg ML. Glatiramer acetate (copolymer-1, copaxone) promotes Th2 cell development and increased IL-10 production through modulation of dendritic cells. J Immunol 2003;170:4483-4488.

22. Stasiolek M, Bayas A, Kruse N, et al. Impaired maturation and altered regulatory function of plasmacytoid dendritic cells in multiple sclerosis. Brain 2006;129(Pt 5):1293-1305.

23. Stuve O, Youssef S, Weber MS, et al. Immunomodulatory synergy by combination of atorvastatin and glatiramer acetate in treatment of CNS autoimmunity. J Clin Invest 2006;116:1037-1044.

24. Fridkis-Hareli M, Strominger JL. Promiscuous binding of synthetic copolymer 1 to purified HLA-DR molecules. J Immunol 1998;160:4386-4397.

25. Teitelbaum D, Milo R, Arnon R, Sela M. Synthetic copolymer 1 inhibits human T-cell lines specific for myelin basic protein. Proc Natl Acad Sci U S A 1992;89:137-141.

26. Aharoni R, Schlegel PG, Teitelbaum D, et al. Studies on the mechanism and specificity of the effect of the synthetic random copolymer GLAT on graft-versus-host disease. Immunol Lett 1997;58:79-87.

27. Webb C, Teitelbaum D, Herz A, Arnon R, Sela M. Molecular requirements involved in suppression of EAE by synthetic basic copolymers of amino acids. Immunochemistry 1976;13:333-337.

28. Wiesemann E, Klatt J, Sonmez D, Blasczyk R, Heidenreich F, Windhagen A. Glatiramer acetate (GA) induces IL-13/IL-5 secretion in naive T cells. J Neuroimmunol 2001;119:137-144.

29. Farina C, Wagenpfeil S, Hohlfeld R. Immunological assay for assessing the efficacy of glatiramer acetate (Copaxone) in multiple sclerosis: a pilot study. J Neurol 2002;249:1587-1592.

30. Lisak RP, Zweiman B, Blanchard N, Rorke LB. Effect of treatment with Copolymer 1 (Cop-1) on the in vivo and in vitro manifestations of experimental allergic encephalomyelitis (EAE). J Neurol Sci 1983;62:281-293.

31. Aharoni R, Teitelbaum D, Sela M, Arnon R. Bystander suppression of experimental autoimmune encephalomyelitis by $\mathrm{T}$ cell lines and clones of the Th2 type induced by copolymer 1 . J Neuroimmunol 1998;91:135-146.

32. Hori S, Nomura T, Sakaguchi S. Control of regulatory $\mathrm{T}$ cell development by the transcription factor Foxp3. Science 2003;299:1057-1061.

33. Brunkow ME, Jeffery EW, Hjerrild KA, et al. Disruption of a new forkhead/winged-helix protein, scurfin, results in the fatal lymphoproliferative disorder of the scurfy mouse. Nat Genet 2001;27:68 73.

34. Fontenot JD, Gavin MA, Rudensky AY. Foxp3 programs the development and function of $\mathrm{CD} 4+\mathrm{CD} 25+$ regulatory $\mathrm{T}$ cells. Nat Immunol 2003;4:330-336.

35. Bacchetta R, Passerini L, Gambineri E, et al. Defective regulatory and effector $\mathrm{T}$ cell functions in patients with FOXP3 mutations. J Clin Invest 2006;116:1713-1722.

36. Sakaguchi S, Fukuma K, Kuribayashi K, Masuda T. Organ-specific autoimmune diseases induced in mice by elimination of $\mathrm{T}$ cell subset. I. Evidence for the active participation of T cells in natural self-tolerance; deficit of a $\mathrm{T}$ cell subset as a possible cause of autoimmune disease. J Exp Med 1985;161:72-87.

37. Kukreja A, Cost G, Marker J, et al. Multiple immuno-regulatory defects in type-1 diabetes. J Clin Invest 2002;109:131-140.

38. Viglietta V, Baecher-Allan C, Weiner HL, Hafler DA. Loss of functional suppression by $\mathrm{CD} 4+\mathrm{CD} 25+$ regulatory $\mathrm{T}$ cells in patients with multiple sclerosis. J Exp Med 2004;199:971-979.

39. Putheti P, Soderstrom M, Link H, Huang YM. Effect of glatiramer acetate (Copaxone) on CD4 $+\mathrm{CD} 25$ high $\mathrm{T}$ regulatory cells and their IL-10 production in multiple sclerosis. J Neuroimmunol 2003;144:125-131.

40. Hong J, Li N, Zhang X, Zheng B, Zhang JZ. Induction of $\mathrm{CD} 4+\mathrm{CD} 25+$ regulatory $\mathrm{T}$ cells by copolymer-I through activation of transcription factor Foxp3. Proc Natl Acad Sci U S A 2005;102:6449-6454.

41. Karandikar NJ, Crawford MP, Yan X, et al. Glatiramer acetate (Copaxone) therapy induces CD8(+) $\mathrm{T}$ cell responses in patients with multiple sclerosis. J Clin Invest 2002;109:641-649.

42. Farina C, Then Bergh F, Albrecht H, et al. Treatment of multiple sclerosis with Copaxone (COP): Elispot assay detects COP-induced interleukin-4 and interferon-gamma response in blood cells. Brain 2001;124(Pt 4):705-719.

43. Tennakoon DK, Mehta RS, Ortega SB, Bhoj V, Racke MK, Karandikar NJ. Therapeutic induction of regulatory, cytotoxic CD8+ T cells in multiple sclerosis. J Immunol 2006;176:7119-7129.

44. Biegler BW, Yan SX, Ortega SB, Tennakoon DK, Racke MK, Karandikar NJ. Glatiramer acetate (GA) therapy induces a focused, oligoclonal CD8 + T-cell repertoire in multiple sclerosis. J Neuroimmunol 2006;180:159-171.

45. Teitelbaum D, Brenner T, Abramsky O, Aharoni R, Sela M, Arnon R. Antibodies to glatiramer acetate do not interfere with its biological functions and therapeutic efficacy. Mult Scler 2003;9:592-599.

46. Farina C, Vargas V, Heydari N, Kumpfel T, Meinl E, Hohlfeld R. Treatment with glatiramer acetate induces specific $\mathrm{IgG} 4$ antibodies in multiple sclerosis patients. J Neuroimmunol 2002;123:188-192.

47. Brenner T, Arnon R, Sela M, et al. Humoral and cellular immune responses to Copolymer 1 in multiple sclerosis patients treated with Copaxone. J Neuroimmunol 2001;115:152-160.

48. Ure DR, Rodriguez M. Polyreactive antibodies to glatiramer acetate promote myelin repair in murine model of demyelinating disease. Faseb J 2002;16:1260-1262.

49. Li Q, Milo R, Panitch H, Swoveland P, Bever CT, Jr.Glatiramer acetate blocks the activation of THP-1 cells by interferon-gamma. Eur J Pharmacol 1998;342:303-310.

50. Hussien Y, Sanna A, Soderstrom M, Link H, Huang YM. Glatiramer acetate and IFN-beta act on dendritic cells in multiple sclerosis. J Neuroimmunol 2001;121:102-110.

51. Jung S, Siglienti I, Grauer O, Magnus T, Scarlato G, Toyka K. Induction of IL-10 in rat peritoneal macrophages and dendritic cells by glatiramer acetate. J Neuroimmunol 2004;148:63-73.

52. Sanna A, Fois ML, Arru G, et al. Glatiramer acetate reduces lymphocyte proliferation and enhances IL-5 and IL-13 production through modulation of monocyte-derived dendritic cells in multiple sclerosis. Clin Exp Immunol 2006;143:357-362.

53. Weber MS, Prod'homme T, Youssef S, et al. Type II monocytes modulate $\mathrm{T}$ cell-mediated central nervous system autoimmune disease. Nat Med 2007;13:935-943. 
54. Allie R, Hu L, Mullen KM, Dhib-Jalbut S, Calabresi PA. Bystander modulation of chemokine receptor expression on peripheral blood $\mathrm{T}$ lymphocytes mediated by glatiramer therapy. Arch Neurol 2005;62:889-894.

55. Zhang M, Chan CC, Vistica B, Hung V, Wiggert B, Gery I. Copolymer 1 inhibits experimental autoimmune uveoretinitis. J Neuroimmunol 2000;103:189-194.

56. Gur C, Karussis D, Golden E, Doron S, Ilan Y, Safadi R. Amelioration of experimental colitis by Copaxone is associated with class-II-restricted CD4 immune blocking. Clin Immunol 2006;118: 307-316.

57. Arnon R, Aharoni R. Mechanism of action of glatiramer acetate in multiple sclerosis and its potential for the development of new applications. Proc Natl Acad Sci U S A 2004;101(Suppl 2):1459314598.

58. Aharoni R, Teitelbaum D, Arnon R. T suppressor hybridomas and interleukin-2-dependent lines induced by copolymer 1 or by spinal cord homogenate down-regulate experimental allergic encephalomyelitis. Eur J Immunol 1993;23:17-25.

59. Kerschensteiner M, Stadelmann C, Dechant G, Wekerle H, Hohlfeld R. Neurotrophic cross-talk between the nervous and immune systems: implications for neurological diseases. Ann Neurol 2003;53:292-304.

60. Kerschensteiner M, Gallmeier E, Behrens L, et al. Activated human $\mathrm{T}$ cells, $\mathrm{B}$ cells, and monocytes produce brain-derived neurotrophic factor in vitro and in inflammatory brain lesions: a neuroprotective role of inflammation? J Exp Med 1999;189:865-870.
61. Hickey WF, Hsu BL, Kimura H. T-lymphocyte entry into the central nervous system. J Neurosci Res 1991;28:254-260.

62. Aharoni R, Kayhan B, Eilam R, Sela M, Arnon R. Glatiramer acetate-specific $\mathrm{T}$ cells in the brain express $\mathrm{T}$ helper $2 / 3$ cytokines and brain-derived neurotrophic factor in situ. Proc Natl Acad Sci U S A 2003;100:14157-14162.

63. Kipnis J, Yoles E, Porat Z, et al. T cell immunity to copolymer 1 confers neuroprotection on the damaged optic nerve: possible therapy for optic neuropathies. Proc Natl Acad Sci U S A 2000;97:7446-7451.

64. Schori H, Kipnis J, Yoles E, et al. Vaccination for protection of retinal ganglion cells against death from glutamate cytotoxicity and ocular hypertension: implications for glaucoma. Proc Natl Acad Sci U S A 2001;98:3398-3403.

65. Angelov DN, Waibel S, Guntinas-Lichius O, et al. Therapeutic vaccine for acute and chronic motor neuron diseases: implications for amyotrophic lateral sclerosis. Proc Natl Acad Sci U S A 2003; 100:4790-4795.

66. Benner EJ, Mosley RL, Destache CJ, et al. Therapeutic immunization protects dopaminergic neurons in a mouse model of Parkinson's disease. Proc Natl Acad Sci U S A 2004;101:94359440.

67. Boska MD, Lewis TB, Destache CJ, et al. Quantitative 1H magnetic resonance spectroscopic imaging determines therapeutic immunization efficacy in an animal model of Parkinson's disease. J Neurosci 2005;25:1691-1700. 